\title{
RESEARCH ON REEF BATHYMETRIC SURVEY OF UAV STEREOPAIR BASED ON TWO-MEDIUM PHOTOGRAMMETRY
}

\author{
Dongmei YE ${ }^{\mathrm{a}}$, Ming LIAO ${ }^{\mathrm{a}}, \mathrm{AO}^{\mathrm{N}}{ }^{\mathrm{a}}$, Enquan WANG ${ }^{\mathrm{b}}$, Gaowei ZHOU ${ }^{\mathrm{b}}$ \\ ${ }^{a}$ ZheJiang TopRS Technology Co., Ltd, Deqing - (ydmtoprs, lming1022, flypoplar)@126.com \\ ${ }^{\mathrm{b}}$ China TopRS Technology Co., Ltd, Beijing - (191620253, 184373223)@qq.com
}

\section{Commission VI, WG VI/4}

KEY WORDS: Bathymetric Survey, Two-medium Photogrammetry, UAV Stereopair, Elevation Correction Coefficient, Underwater Reefs

\begin{abstract}
:
This paper is based on the principles of two-medium photogrammetry, with the purpose to perform a bathymetric survey of a reef in the South China Sea, using aerial imagery acquired by UAV. The first objectives are to introduce the basic principles of two-medium photogrammetry, discuss the technical requirements of this methodology to determine an accurate refractive index of sea water, and propose a new method to calculate seawater refraction and calculate corrected reef elevations. The second objective is to analyse and integrate the elevation and depth datum for both the land mass and the undersea reef. The final objective of this paper is performing stereoscopic mensuration on the UAV photography in order to transform reef elevation and depth datum. Our test shows that aerial two-medium photogrammetry is feasible in practical application, but requires relatively high aerial photography conditions.
\end{abstract}

\section{INTRODUCTION}

Bathymetric surveys of the reefs surrounding the offshore islands are primarily performed by sonar surveys, which require considerable manpower and expensive. Scholars are now using remote sensing techniques to survey these sites. Multi-spectral satellite data is used for water depth inversion, a technique which on the control point and retrieval model. However this technique is imprecise and difficult for most engineering applications. Another potential method for undersea mapping is two-medium photogrammetry, but to date there has been little practical application. Some theoretical study has been accomplished:

C.Linus\&R.Burkhardt (1979) has given a simple discussion for two-medium. Y.N.Wang (1988) completed some two-medium mapping software and some research on the underwater topography mapping while at Xi'an Institute of Surveying and Mapping. B.Y.Chang (1991) derived some basic formulas of two-medium photogrammetry. J.Shan (1993) proposed the processes of the two-medium photogrammetry on the relative orientation on the basis of two-medium rays and coplanarity. S.L.Liu (2011) studied the direct referenced relative orientation calculation methods of airborne POS systems, based on the two-medium photogrammetry.

Aerial two-medium photogrammetry provides high spatial resolution to describe submarine topographical features required for the $3 \mathrm{D}$ landscape model, although the water depth measurement and detection precision are lower accuracy than terrestrial mapping. This paper combines the flexible UAV image acquisition capability with bathymetric surveys using two-medium photogrammetric techniques. Our first objective is to analyse the basic two-medium photogrammetric theory. ${ }^{1}$

The second objective is to describe the test process in detail, outline the key technical problems, and provide the results with an analysis. The third objective is to summarize the deficiencies in our method and the significance to our test results.

\footnotetext{
${ }^{*}$ Dongmei YE
}

\section{IMPROVED ALGORITHM FOR TWO-MEDIUM PHOTOGRAMMETRY}

\subsection{Research situation of two-medium photogrammetric technique}

Z.Z.Wang (1979) describe the two-medium photogrammetry definition is the technology of using image space and object space of images taken in two different media to determine the geometrical characteristics of the subject target.

Two-medium photogrammetry basic algorithm is as follows:

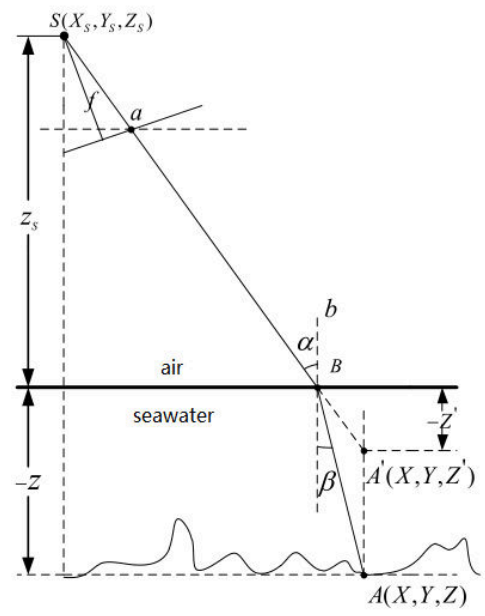

Figure1. Concept diagram of two-medium photogrammetry

Figure1 shows the conformational relationship among the object space point $A(X, Y, Z)$, image space point $a(x, y)$ and the perspective center image $S\left(X_{S}, Y_{s}, Z s\right)$. In contrast to traditional photogrammetry, the photo center is noncollinear with the points of object space and image space in two-medium photogrammetry.

Assume the photogrammetric plane coordinate system XOY is parallel to the local tangent plane with the $\mathrm{Z}$ axis 
perpendicular to plane $\mathrm{XOY}$ and that the sea surface is also parallel. Figure 1 shows the underwater point $A(X, Y, Z)$ is represented as image point $a(x, y)$. According to refraction principle, the image point $a(x, y)$ intersects with the point $A^{\prime}\left(X, Y, Z^{\prime}\right)$ in the substrate space. The point $A^{\prime}\left(X, Y, Z^{\prime}\right)$ projects above the point $A(X, Y, Z)$, and has the same planimetric coordinate.

\section{(1) Collinearity equation}

As shown in Figure 1,

$$
Z^{\prime}=Z \cdot \tan \beta \cdot \cot \alpha
$$

Where $\alpha=$ the angle of incidence

$\beta=$ the angle of refraction

$\mathrm{Z}=$ the $\mathrm{Z}$-coordinate of point $A$

$Z^{\prime}=$ the $Z$-coordinate of point $A$ '

And the law of refraction:

$$
\frac{\sin \alpha}{\sin \beta}=\frac{n_{2}}{n_{1}}=n
$$

Where $n_{1}=$ the first medium refractive index

$n_{2}=$ the second medium refractive index

As shown in the Equation (2-2), the refractive index of the air medium is $1, n$ as the other medium. Calculating the Equations (2-1) and (2-2) we obtain Equation (2-3) as follows:

$$
Z^{\prime}=Z / \sqrt{n^{2}+\left(n^{2}-1\right) \tan ^{2} \alpha}=Z / s
$$

In Equation (2-3),

$$
s=\sqrt{n^{2}+\left(n^{2}-1\right) \tan ^{2} \alpha}
$$

Where $\quad \alpha=$ the angle of incidence

$$
s=\text { the elevation correction coefficient by refraction }
$$

L.G.Jiang\&P.Sun researchers (2002) generally take the refractive index $n$ as $4 / 3$. The maximum water depth in which object detection is possible in two-medium photogrammetry is theoretically $30 \mathrm{~m}$ with millimetre accuracy. Sea water refractive error in two-medium photogrammetry is observed as minimal and accepting the refractive index $n$ as $4 / 3$ meets measurement requirements.

Combining Equation (2-3) and the traditional collinearity equations, we can obtain the two-medium collinearity equations as follows:

$$
\left\{\begin{array}{l}
x=-f \frac{a_{1}\left(X-X_{S}\right)+b_{1}\left(Y-Y_{S}\right)+c_{1}\left(Z / s-Z_{S}\right)}{a_{3}\left(X-X_{S}\right)+b_{3}\left(Y-Y_{S}\right)+c_{3}\left(Z / s-Z_{S}\right)} \\
y=-f \frac{a_{2}\left(X-X_{S}\right)+b_{2}\left(Y-Y_{S}\right)+c_{2}\left(Z / s-Z_{S}\right)}{a_{3}\left(X-X_{S}\right)+b_{3}\left(Y-Y_{S}\right)+c_{3}\left(Z / s-Z_{S}\right)}
\end{array}\right.
$$

Where $f=$ focal length

$s=$ the elevation correction coefficient

$(x, y)=$ image coordinates

$\mathrm{a}_{1}, \mathrm{a}_{2}, \mathrm{a}_{3} \ldots \mathrm{c}_{1}, \mathrm{c}_{2}, \mathrm{c}_{3}=$ the direction cosine

$$
\begin{aligned}
& \left(X s, Y_{s}, Z_{s}\right)=\text { coordinates of projection center } \\
& (X, Y, Z)=\text { the object coordinates }
\end{aligned}
$$

\section{(2) Coplanarity condition equation}

The auxiliary space coordinate system takes the left image photo centre as the origin coordinate and the photogrammetric coordinate system take the point parallel to the medium interface as the origin coordinate; $\left(X_{S L}, Y_{S L}, Z_{S L}\right)$, $\left(X_{S R}, Y_{S R}, Z S R\right)$ are the photo center coordinates of the left and right images. If $B_{X}=X_{S R}-X_{R L}, B_{Y}=Y_{S R}-Y_{S L}, B Z=Z_{S R}-Z_{S L}$ the coplanarity condition equation of two-mediums is as follows:

$$
\left|\begin{array}{ccc}
B_{X} & B_{Y} & s_{2} Z_{S R}-s_{1} Z_{S L} \\
\bar{x}_{1} & \bar{y}_{1} & s_{1} \bar{z}_{1} \\
\bar{x}_{2} & \bar{y}_{2} & s_{2} \bar{z}_{2}
\end{array}\right|=0
$$

Where

$\left(\bar{x}_{1}, \bar{y}_{1}, \bar{z}_{1}\right)=$ transformation coordinates of left image points $\left(\bar{x}_{2}, \bar{y}_{2}, \bar{z}_{2}\right)=$ transformation coordinates of right image points $s_{1}=$ the elevation correction coefficient of left image $s_{2}=$ the elevation correction coefficient of right image

(3) The point projection coefficients between the left and right images

Use the Equation (2-6) to calculate the left and right image projection coefficients $N_{1}, N_{2}$ of homonymy points:

$$
\left\{\begin{array}{l}
N_{1}=\left|\begin{array}{cc}
B X & s_{2} Z s R-s_{1} Z s L \\
\bar{x}_{2} & s_{2} \bar{z}_{2}
\end{array}\right| /\left|\begin{array}{cc}
\bar{x}_{1} & s_{1} \bar{z}_{1} \\
\bar{x}_{2} & s_{2} \bar{z}_{2}
\end{array}\right| \\
N_{2}=\left|\begin{array}{cc}
B_{X} & s_{2} Z s R-s_{1} Z s L \\
\bar{x}_{1} & s_{1} \bar{z}_{1}
\end{array}\right| /\left|\begin{array}{cc}
\bar{x}_{1} & s_{1} \bar{z}_{1} \\
\bar{x}_{2} & s_{2} \bar{z}_{2}
\end{array}\right|
\end{array}\right.
$$

(4) The vertical parallax solution

$$
Q=N_{1} \bar{y}_{1}-N_{2} \bar{y}_{2}-\left(Y_{S R}-Y_{S L}\right)
$$

(5) The object space coordinate of the target point solution

$$
\left\{\begin{array}{l}
X=\frac{1}{2}\left(X S L+N_{1} \bar{x}_{1}+X S R+N_{2} \bar{x}_{2}\right) \\
Y=\frac{1}{2}\left(Y S L+N_{1} \bar{y}_{1}+Y S R+N_{2} \bar{y}_{2}\right) \\
Z=\frac{1}{2}\left(\left(Z S L+N_{1} \bar{z}_{1}\right) s_{1}+\left(Z S R+N_{1} \bar{z}\right) s_{2}\right)
\end{array}\right.
$$

\section{(6) The elevation correction factor solution}

Prior to our elevation correction coefficient solution research, the Equations (2-10) and (2-11) were used to iteratively calculate the elevation correction coefficient of the left and right images.

$$
\begin{aligned}
\operatorname{tg} \alpha & \approx\left(X-X_{S L}\right) / Z_{s L} \\
\operatorname{tg} \alpha & =\frac{R}{Z_{S}-Z / s}
\end{aligned}
$$


This method requires the input of an initial estimate for the coefficient and if the estimate is incorrect then the solution will not converge, hence $s_{1}$ and $s_{2}$ will not be calculated.

\subsection{Improved Algorithm to compute elevation correction factor}

In this paper, the elevation correction factor has been further improved to avoid the drawbacks of the iterative algorithm. In the case of obtaining accurate interior and exterior orientation elements, we take the incident rays and refraction rays as vectors of $a$ and $b$ in order to calculate the angle of incidence directly. The algorithm calculated as follows:

$$
\cos \alpha=\frac{a \cdot b}{|a| \cdot|b|}
$$

Where

$a$ and $b=$ the vectors of $a A^{\prime}$ and $A^{\prime} b$ in the same image space coordinate system

$\alpha=$ the angle between vector $a A^{\prime}$ and $A^{\prime} b$

In the Equation (2-12), $a A$ ' vector coordinate in image space coordinate system can be obtained with image space coordinate of image point by multiplying the rotation matrix $R$, and assign the $A^{\prime} b$ vector coordinate as $(0,0,-1)$ to substitute into the vector Equation (2-12) to obtain $\alpha$, and then solve $\operatorname{tg} \alpha$.

Then substitute Equation (2-12) into Equation (2-13) to calculate the elevation correction factors $s$ of the left and the right image respectively.

$$
s=\sqrt{n^{2}+\left(n_{2}-1\right) \operatorname{tg}^{2} \alpha}
$$

Since the observable incidence angle of the same point in different images are unique, we need to solve each of the image points elevation correction factor $s$ in both the left and right images, in order to gain elevation of underwater reef.

\section{ELEVATION AND DEPTH DATUM UNITY}

The photogrammetrically derived reef elevation coordinates are based in the 1985 National Height Datum (also known as annual average sea surface elevation at the origin) and the reef depth results are based on depth datum. These disparate datums need to be unified to complete the analysis. Though this is not part of the focus of this study, we just make the brief explanation that follows.

\section{(1) Relative elevation of 1985 National Height Datum solved}

Numerically, the surface elevation anomaly values can be obtained from reference ellipsoid and quasigeoid by geoid refine technology, and then get the elevation $h_{l}$ of the island based on 1985 National Height Datum on CGCS2000 ellipsoid.

\section{(2) Relative elevation of depth datum solution}

Reference to the mean sea surface, according to the local tidal parameters of many years, we can down to calculate the relative elevation of theoretical depth datum surface; upward to take the average high tide line as the coastline; in the intertidal area that is called beach. Through the above calculated in theory, we can get the elevation position of depth datum on CGCS2000 ellipsoid.

\section{(3) Basis of uniform elevation and depth conversion}

We can get the difference value between the 1985 National Height Datum and the depth datum $\Delta h=h_{1}-h_{2}$ indirectly. By stereoscopic measure, reef elevation is $-Z$ on the 1985 National Height Datum, which depth value $z=Z-\Delta h$.

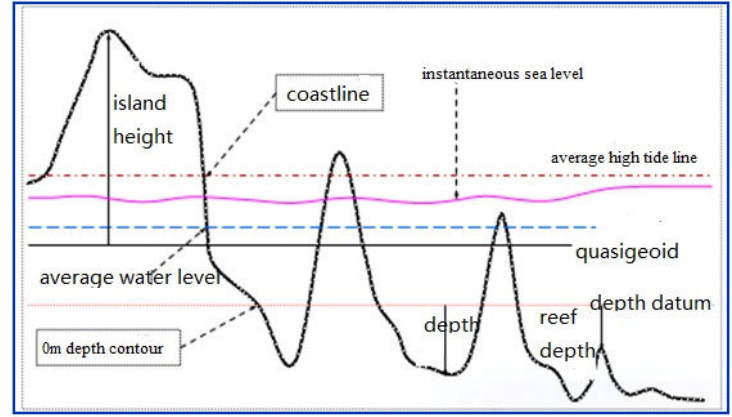

Figure2. Island vertical datum relationship

\section{EXPERIMENTAL VERIFICATION}

\subsection{Profile of the test area}

\section{(1) Study area}

In the South China Sea, the seawater has little turbidity which allows quite effective stereo mensuration for underwater reefs. We selected an island as the experimental area where the reef is arc-shaped and $7 \mathrm{~km}$ long north-south and $5 \mathrm{~km}$ wide east to west for a total of about $22 \mathrm{~km}^{2}$. The reef scope is shown below as Figure3.
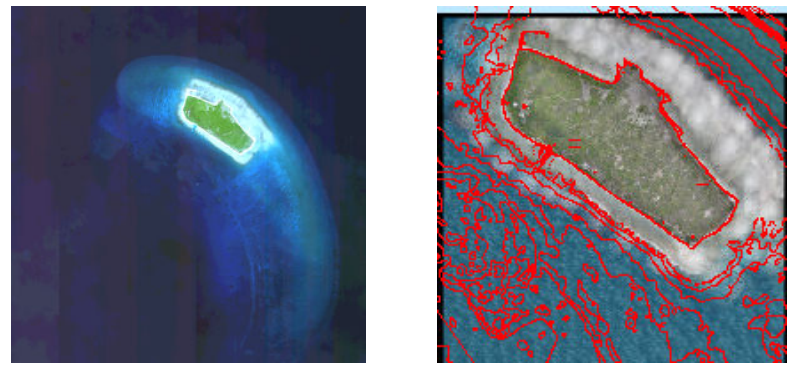

Figure 3. Reef distribution scope

Figure 4. Field bathymetric

\section{(2) Introduction of UAV data}

For our test we used $0.1 \mathrm{~m}$ ground resolution imagery from a $\mathrm{UAV}$ of the reef along with exterior orientation parameters that are capable to meet 1:2000 mapping accuracy with CGC2000 and 1985 National Height Datum.

\section{(3) Introduction of field bathymetric data}

The field bathymetric survey data around the island included bathymetric survey points and handling generated depth contours. The field bathymetric survey range is as shown in Figure 4. The surveying results meet 1:5000 scale mapping; the depth measurement accuracy is $\pm 0.3 \mathrm{~m}$, CGCS 2000, Gauss - 
Kruger projection with a zone width of 1.5 degrees and a central meridian of 114 degrees.

\section{(4)Weather and sea conditions}

The island image was acquired by a UAV on May 13, 2011 11:40-13:00. According to National Maritime Bureau website, the weather was rainy with 4-5 degree wind and $1.5 \mathrm{~m}$ waves.

\subsection{Technical process of reef bathymetric survey with UAV}

\section{(1) Reef stereoscopic mensuration}

Collect the information of the underwater reef by stereoscopic measurement using the results of aerial triangulation.

\section{(2) Reef elevation calculation}

Implement the two-medium photogrammetric model to calculate the reef elevation.

\section{(3) Reef depth calculation}

Use the results of the tidal model to calculate the reef depth (which is based on depth datum) from elevation (which is based on 1985 National Height Datum).

\section{(4) Reef depth accuracy assessment}

Compare the calculated reef depth with field bathymetric data to evaluate the accuracy on the depth datum reference plane. The experimental technique flowchart is shown in Figure5.

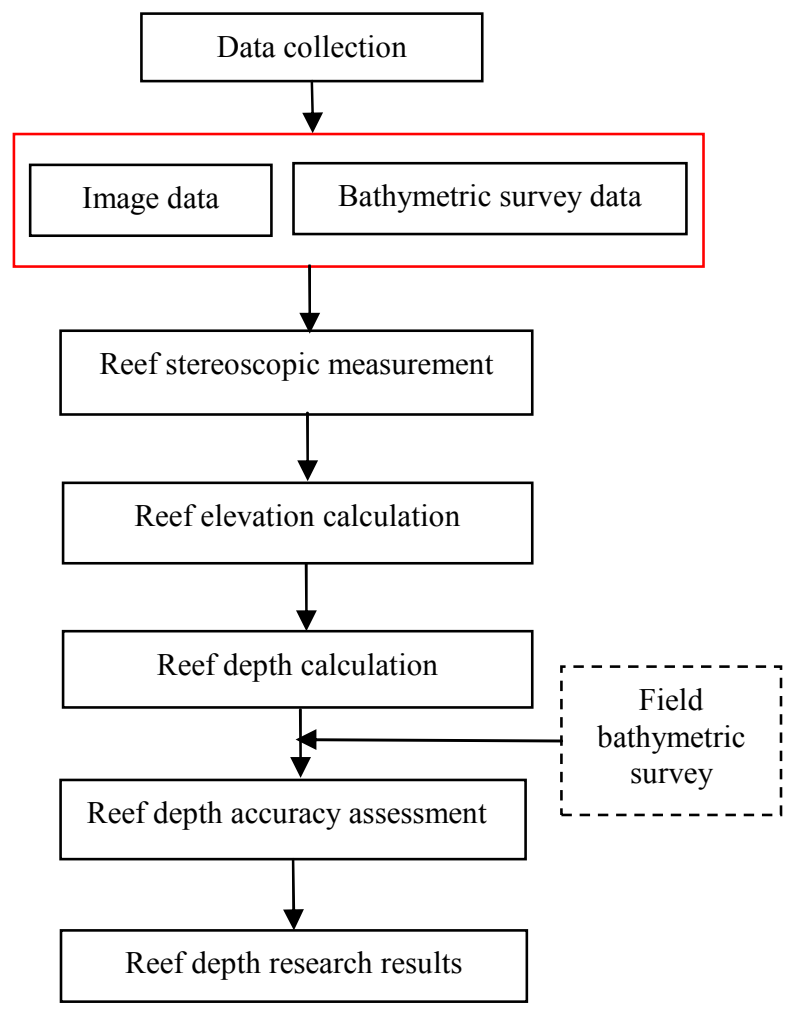

Figure 5. Experimental technique flowchart

\subsection{Reef stereoscopic measurement}

Use the digital aerial triangulation result with image coordinates, exterior orientation elements and other information to restore the stereopair to gather reef image coordinates individually. The collected point coordinate distribution is shown in Figure6.

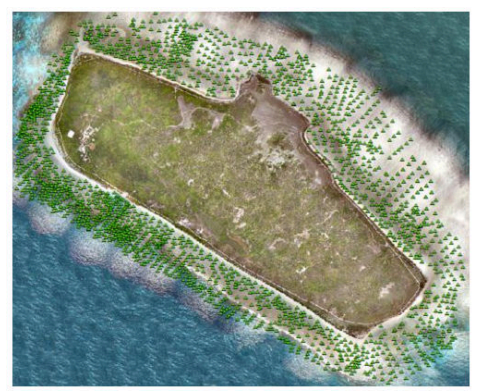

Figure6. Distribution of collected reef point chart

As shown in Figure6, the reef points are not evenly but distributed as explained below:

1) Too few homologous image points to aerial triangulate, images of only seawater cannot be oriented without precise exterior orientation elements.

2) Point matching fails where there is poor contrast in the imagery and the resultant exterior orientation values contain excessive parallax, rendering stereo mensuration impossible.

3) Poor weather conditions during acquisition caused poor lighting conditions in the imagery and large surf obscured clear vision of the reef.

\subsection{Reef elevation calculation}

When solving the reef elevation using two-medium photogrammetric model, we first need to determine the elevation from photographic center to the sea surface. The island images are photographed by May 13, 2011 with $1.5 \mathrm{~m}$ height waves, so we can't directly use the instantaneous water level elevation $0.42 \mathrm{~m}$ deduced by theory. In our experiment, we interpret the reliable instantaneous water points to calculate the average elevation as the medium elevation. Then use twomedium photogrammetric algorithm and image coordinates individually to calculate the reef elevation in 1985 National Height Datum.

\subsection{Reef depth calculation}

1) Adopt geoid refine model and sea surface topographic model to calculate the height anomaly value is $5.33 \mathrm{~m}$ between the 1985 National Height Datum and CGCS2000 ellipsoid.

2) According to the average sea surface height model and geoid refine model, the projected average sea elevation on the ellipsoid is $6.03 \mathrm{~m}$ (mean sea level projection accuracy is 10 $\mathrm{cm}$ ); Then use the height $6.03 \mathrm{~m}$ and historical tidal data to calculate The island's depth datum height is $4.64 \mathrm{~m}$ on CGCS2000 ellipsoid.

3) Therefore, the difference $\Delta h$ between the 1985 National Height Datum of $5.33 \mathrm{~m}$ and the depth datum height of $4.64 \mathrm{~m}$ is $0.69 \mathrm{~m}$ on the CGCS2000 ellipsoid. 
In order to facilitate to comparison between the precision depths data with the field bathymetric survey data, and to carry out the integration of the island and underwater reef mapping, we take the reef results with two different methods to unify to 1985 National Height Datum.

\subsection{Accuracy evaluation}

In this experiment, the reef coordinates of the results are scattered so we adopt TerraSolid software to compute the elevation accuracy evaluated using the following method: Firstly, treat the field bathymetric survey points coordinate result as true value to construct triangulated irregular network (TIN) shown in Figure7.

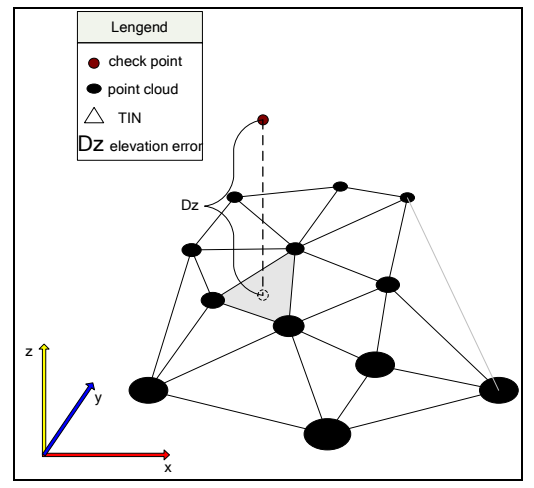

Figure7. Principle of accuracy assessment

Secondly, treat the calculated reef points coordinate result as checked value, and determine the projection triangle along the $\mathrm{Z}$-axis direction in the TIN; Finally, take the $\mathrm{X}$ and $\mathrm{Y}$ value to calculate $Z$ projection values of this triangle, denoted as $Z_{1}$ and get the elevation error $\mathrm{Dz}$ with $\mathrm{Z}_{1}-\mathrm{Z}$.

The depth of the reef is calculated for each stereopair; therefore the overall accuracy of the survey area is evaluated by each independent stereopair, the results show in the table below.

\begin{tabular}{|c|c|c|c|c|c|}
\hline \multirow{2}{*}{ No. } & $\begin{array}{c}\text { Routes -image } \\
\text { number, } \\
\text { stereopair } \\
\text { number }\end{array}$ & $\begin{array}{c}\text { The average } \\
\text { sea surface } \\
\text { elevation } \\
\text { values (m) }\end{array}$ & \multicolumn{3}{|c|}{ Accuracy (m) } \\
\cline { 4 - 6 } & STDEV & RMS & AVE Dz \\
\hline 1 & $5-15,378-376$ & 1.83 & 0.10 & 0.09 & -0.80 \\
\hline 2 & $5-14,380-378$ & 1.41 & 0.40 & 0.39 & -0.46 \\
\hline 3 & $5-13,382-380$ & 1.09 & 0.74 & 0.73 & 0.78 \\
\hline$\ldots$ & $\ldots$ & $\ldots$ & $\ldots$ & $\ldots$ & $\ldots$ \\
\hline 31 & $4-16,478-480$ & 1.87 & 0.62 & 0.61 & -0.53 \\
\hline \multicolumn{7}{|l}{ Total accuracy of the survey area } & $\mathbf{0 . 6 2}$ & $\mathbf{0 . 6 8}$ & $\mathbf{0 . 5 2}$ \\
\hline
\end{tabular}

Table1. The accuracy of two-medium photogrammetry

\subsection{Integration of island and underwater reef mapping}

Based on 1985 National Height Datum, the test unified the island and underwater reef to construct and cartographically render one DEM. Due to the limit of the two-medium photogrammetric method to stereoscopically observe the underwater reef, coupled with strong reflective images, corrugated, etc., we construct the uneven distribution DEM as shown in Figure8 below:

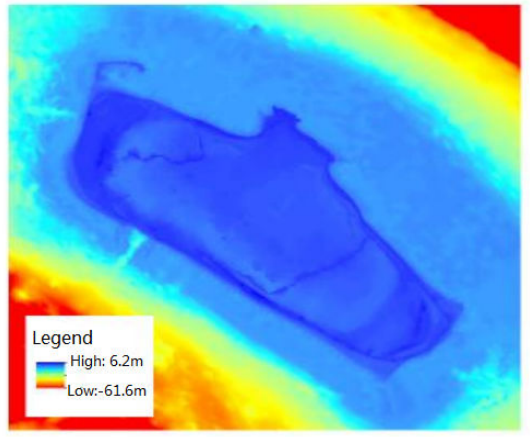

Figure8. Island and underwater reef DEM shading map

\section{CONCLUSION}

The seawater depth measurement error of the island is 0.68 meters based on the two-medium photogrammetric method. Assuming the image quality meets the requirement the twomedium photogrammetric technique is feasible to map reef depth in shallow water. The technique does require that each image has precise exterior orientation parameters, which can be a challenge in open water. Our future efforts in under water reef depth mapping will include larger reefs implementing satellite imagery with superior spectral fidelity to enhance the two-medium photogrammetry.

\section{ACKNOWLEDGEMENTS}

Thanks to Prof. J.Y. Bao of Dalian Naval Academy of the PLA have done great contribution to solve the elevation and depth datum.

\section{REFERENCES}

Z.Z, Wang, 1979. Principles of photogrammetry. In: Beijing: The publishing house of Surveying and mapping.

C.Linus \& R.Burkhardt, 1979. Photogrammetry. In: Beijing:The publishing house of Surveying and mapping.

MODUNCE L E, 1979. Underwater Photography.W.D.Zhang, trans. In: Beijing: Science Press.

LIR, LIH,ZOU W, et al, 1997. Quantitative photogrammetric analysis of digital underwater video imagery. In: IEEE Jouranl of Oceanic Engineering, 22(2), pp. 364-375.

MAAs H G, 1995. New developments in multimedia photogrammertry. In: Optical 3D measurement techniques III.

GILI T, SAGI F, 2010. Photogrammetric modeling of underwater environments. ISPRS Journal of Photogrammetry and Remote Semote Sensing, 65(5), pp. 433-444.

Y.B.Chang, 1991. Basis formulas of two-media photogrammetry. Acta Geodaetica Cartogra phicaSinica, 20(4), pp. 288294.

Y.N.Wang, H.Ling, Y.Wang, 1988. Experimental study of close range photogrammetry underwater. Journal of Surveying and mapping, 17(3), pp. 217-224. 
S.L.Liu, Y.D.Zhao, Y.C.Ling, Y.L.Xue, 2011. Analysis at underwater topographict two-media photogrammetry with POS data. In: Science of Surveying and Mapping, 36(6), pp. 42-45.

Y.M.Dang, P.F.Cheng, C.Y.Zhang, X.M.Tang, Y.C.Li, 2012. Sea reefs mapping technology and methods. In: Beijing: Surveying and mapping press.

X.H.Quan, S.Fry Edward, 1995. Empirical equation for the index of refraction of seawater. In: Applied oftics, 34(18), pp. 3477-3480.

L.G.Jiang\&P.Sun, 2002. Models of the waterlength dependence for the index of refraction. In: Chinese Journal of Spectroscopy Labor atory, 19(4), pp. 554-556.

Z.X.Zhang\&J.Q.Zhang, 2012. Digital Photogrammetry. In: Wuhan:Wuhan University Press.

J.S.Shen, 2011. Research on technology of equal waterline information extraaction and vertical datum transformation in coastal zone.

J.Y.Bao, C.Y.Zhang, 2010. On the sea and ocean vertical datum. Bulletin of Surveying and Mapping, 26(6), pp. 10-11.

B.Y. Chang, 1991. The basic formula of double medium photogrammetry.In: Journal of Surveying and mapping, 20(4), pp. 288-294.

J. Zhang,1993. The relative orientation of two medium photogrammetry. In: Journal of PLA Institute of Surveying and mapping, pp. 38-44.

J.Q. Zhang, L. Pan, S.G. Wang, 2002. Photogrammetry. In: Wuhan:Wuhan University press.

H. Xiao, Q. Edward, S.Fry, 1995. Empirical equation for the index of refraction of seawater. In: Applied optics, 34(18), pp. 3477-3480.

S.L.Liu, Y.C.Li, G.D.Zhao, 2011. Analysis at underwater topographic two-media photogrammetry in POS data. In: Science of Surveying and Mapping,37(8), pp.20-24.

Y.J.Bao, 2000. Marine datum establishment, calibration and maintenance. In: Hydrographic Surveying and Charting, (4), pp. 4-8.

Y.J. Bao, Y.C. Liu, 2003. Study on the chart datum algorithm. In: Hydrographic Surveying and Charting, (1), pp. 8-12.

Y.J. Bao, C.Y. Zhang, 2001. Discussion on the ocean vertical datum. In: Bulletin of Surveying and mapping (6), pp. 10-11. 